This document is confidential and is proprietary to the American Chemical Society and its authors. Do not copy or disclose without written permission. If you have received this item in error, notify the sender and delete all copies.

\title{
Atomistic Model of Realistic Crystalline Mesoporous Organosilica Materials Including Nanochannels
}

\begin{tabular}{|r|l|}
\hline Journal: & The Journal of Physical Chemistry \\
\hline Manuscript ID & Draft \\
\hline Danuscript Type: & Article \\
\hline Complete List of Authors: & $\begin{array}{l}\text { De Nicola, Antonio; Yamagata University, Organic Materials Science } \\
\text { Correa, Andrea; University of Salerno, Chemical Science } \\
\text { Comotti, Angiolina; University of Milano Bicocca, Department of Materials } \\
\text { Science } \\
\text { Sozzani, Piero; University of Milano Bicocca, Department of Materials } \\
\text { Science } \\
\text { Milano, Giuseppe; Yamagata Daigaku, Organic Materials Science }\end{array}$ \\
\hline
\end{tabular}


Atomistic Model of Realistic Crystalline

\title{
Mesoporous Organosilica Materials Including
}

\section{Nanochannels}

\author{
Antonio De Nicola, ${ }^{* \dagger}$ Andrea Correa, ${ }^{\ddagger}$ Angiolina Comotti, $₫$ Piero Sozzani, $₫$ and \\ Giuseppe Milano*,† \\ $\dagger$ Department of Organic Materials Science, Yamagata University, 4-3-16 Jonan Yonezawa, \\ Yamagata-ken 992-8510, Japan. \\ $\ddagger$ Department of Chemical Sciences, Federico II University of Naples Via Cintia, Complesso \\ Monte S. Angelo, 80126 Napoli, Italy. \\ \Department of Materials Science and INSTM, University of Milano Bicocca, Via R.Cozzi \\ 55, I-20125 Milan, Italy. \\ E-mail: adenicola@yz.yamagata-u.ac.jp; gmilano@yz.yamagata-u.ac.jp
}

\begin{abstract}
The new class of periodic mesoporous ogranosilicas materials (PMOs), due to the peculiar features, attracts growing interest from several research areas. We present an atomistic model of $p$-phenylenesilica crystalline mesoporous structure with a hexagonal framework, explicitly including channels on nanoscale. OPLS-AA force field optimization, to get suitable PMO structure compared with experimental one, is described. In particular, DFT calculation have been performed to calculate torsional energy barrier of phenyl rings connected to the silicon atoms belonging inorganic layers. Finally, the gas insertion and interaction of them with nanochannel walls are investigated.
\end{abstract}




\section{Introduction}

Periodic mesoporous organisilicas (PMOs) are a new class of materials ${ }^{1}$ of particular interest due to the potential applications in several areas such as: gas storage, ${ }^{2,3}$ confined polymerization, ${ }^{4}$ molecular rotors,${ }^{3-6}$ selective adsorption,,${ }^{3,7}$ catalysis,${ }^{8}$ molecular rotors,${ }^{9}$ adsorbent for pollutes from air and water, ${ }^{10,11}$ and even water desalination. ${ }^{12}$

The high technological impact of PMOs with large specific surface area makes the development of this materials a currently expanding research area. Since 1999 when Inagaki, ${ }^{13}$ Asefa $^{14}$ and Melde ${ }^{15}$ reported firsts successful synthesis of bridge-bonded species $(\mathrm{RO})_{3} \mathrm{Si}-\mathrm{R}_{9}-\mathrm{Si}(\mathrm{OR})_{3}$, in which $\mathrm{Si}-\mathrm{C}$ bonds are integrated into walls of a mesoporous silica matrix, the synthesis of hybrid organic-inorganic materials has become well established. Today, PMOs materials are commonly produced by hydrolytic and polycondensation reactions of precursors of type $(\mathrm{RO})_{3} \mathrm{Si}-\mathrm{R}-\mathrm{Si}(\mathrm{OR})_{3}$ known as sol-gel process. ${ }^{16-20}$ By choosing specific R group, homogeneously within inorganic framework, a variety of features, such as surface hydrophobicity or accessible free volume, can be controlled. ${ }^{2,21-23}$

Due to the peculiar structure, PMOs materials have unique features: chemically reactive sites homogeneously distributed, high of organic content; mesoporous channels; high surface area, high accessible free volume, fine tuning of the physical properties by chemical functionalization. In particular, PMOs with crystalline-like order in their walls ${ }^{13-15,24}$ have organosiloxane units organized into ordered layers with molecular axes parallel to the mesochannel axis. Mesoporous organosilica crystalline structure exhibits a hexagonal framework with nanochannels having both, mesoscale periodicity and molecular order, as reported by Inagaki. ${ }^{24}$ The combination of ordered organic/inorganic layers at wall nanochannel interface makes interactions of PMOs with guest species one of the key feature of adsorption/desorption properties from both, fundamental and applicative points of view.

From the theoretical point of view and to the best of our knowledge, only a DFT study of PMOs investigating gas adsorption energy have been reported, ${ }^{25}$ while, silica $\left(\mathrm{SiO}_{2}\right)$ structures, crystalline and amorphous, ${ }^{26-32}$ and organosilicate ${ }^{26,33}$ have been extensively studied. 
In particular, DFT studies have been reported to investigate water adsorption on $\alpha$-quartz surfaces, ${ }^{31,32}$ while, combining Molecular Dynamics (MD) and the reactive bond-order based force field ReaxFF, ${ }^{34}$ the stability of hydroxylated silica surface and crack propagation were investigated. ${ }^{28-30}$ By using the same ReaxFF, Du et.al recently reported a study about nanoporouse organosilicate glasses ${ }^{33}$ in which a nanoporouse silica systems were functionalized with methyl groups and short hydrocarbon chains.

Our aim is to model and validate, at atomistic level and by using MD technique, a realistic structure of crystalline mesoporous organosilica. The paper is organized as following. In the next section the atomistic model and the force field optimization of crystalline precursor of PMOs, to get a correct description of the main interactions we will have in the hybrid mesoporous material, is reported. The procedure to get $p$-phenylenesilica crystalline mesoporous structure and force-field validation is reported in the Result and Discussion section. A first application investigating gas adsorption properties of PMO material is also given in the same section. The summary of the main results is given in the Conclusion section.

\section{Methods and Model}

Due to the chemical similarity to the PMOs, OPLS-AA force field ${ }^{35}$ have been tested to reproduce the PMOs crystalline precursor structure reported by Corriu. ${ }^{36}$ On the basis of experimental X-Ray data, ${ }^{36}$ the Cartesian coordinates of PMOs precursor crystalline structure have been generated by using Mercury CSD 2.0 Code. ${ }^{37}$ In particular, a single unit cell of 1,4-Bis(trihidroxysilil) Benzene (BTHB) has been replicated five times in each $x, y, z$, direction, obtaining a periodic structure composed by 14400 atoms. The chemical structure of (BTHB) together with crystalline unit cell representation are reported in Figure 1.

The consistency of the BTHB crystalline structure has been checked by comparison the calculated X-Ray pattern with those one experimentally reported. ${ }^{36}$ We did not observe relevant differences between both X-Ray patterns, confirming that the obtained crystalline 


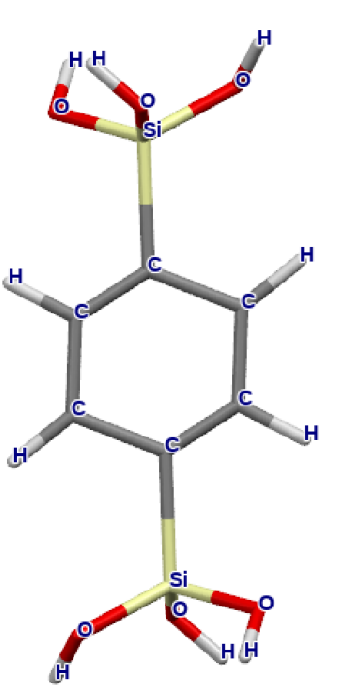

1,4-Bis(trihydroxysilil)benzene

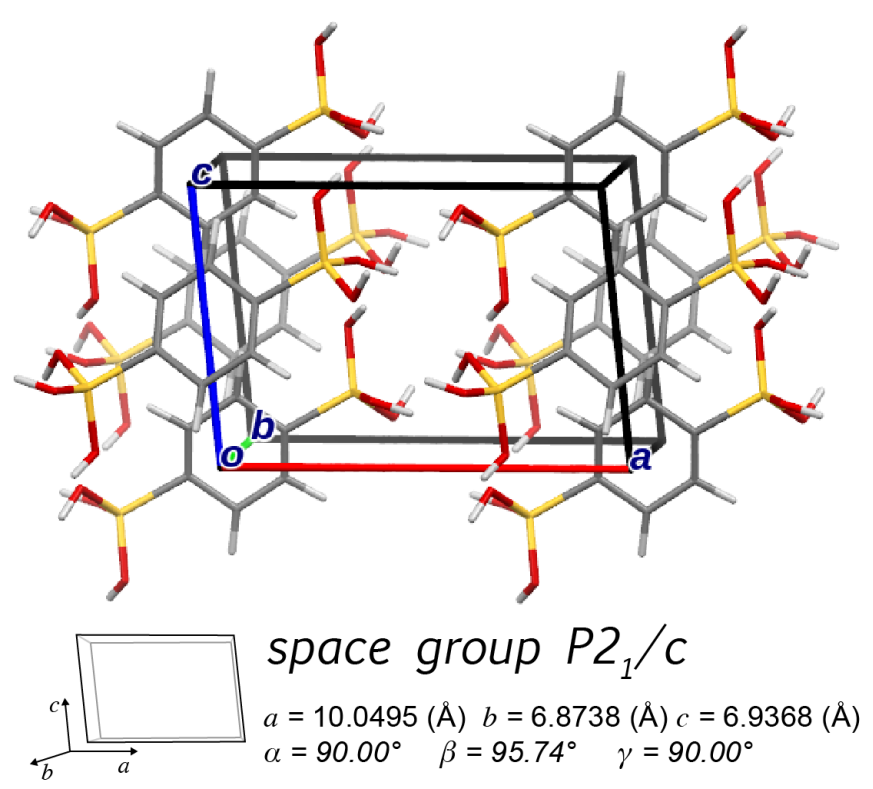

Figure 1: Chemical structure of BTHB on left. Crystalline unit cell, built from fractional atomic coordinates ${ }^{36}$ in the right panel. Hydrogen atoms have been manually added by considering the bond distances and bending angle of the OPLS-AA force-field. ${ }^{35}$

structure of BTHB is consistent with the experiments.

OPLS-AA atomistic force-field ${ }^{35}$ has been used for the majority of bonded and non bonded interactions, excluding those ones involving silicon atoms. In particular, bond and angle potential are calculated as:

$$
\begin{aligned}
& E_{\text {bond }}=\sum_{\text {bonds }} K_{B}\left(r-r_{e q}\right)^{2} \\
& E_{\text {angle }}=\sum_{\text {angles }} K_{\theta}\left(\theta-\theta_{e q}\right)^{2}
\end{aligned}
$$

Where $K_{B}$ is the bond constant of the harmonic potential, $r_{e q}$. is the equilibrium distance between two bonded atoms, $K_{\theta}$ is the angle bending constant and $\theta_{0}$ is the equilibrium angle between three consecutive bonded atoms.

The torsional intra molecular energy is calculated as the sum of first three terms of Fourier series as:

$$
E(\phi)=\frac{V_{1}}{2}[1+\cos (\phi+f 1)]+\frac{V_{2}}{2}[1+\cos (2 \phi+f 2)]+\frac{V_{3}}{2}[1+\cos (3 \phi+f 2)]
$$


Where $\phi$ is the dihedral angle between for consecutive bonded atoms and $V_{1}, V_{2}, V_{3}$ are the Fourier coefficients series, instead f1, f2, f3 are the angle phases.

The sum of Coulomb and Lennard-Jones (LJ) terms are used to represents the non-bonded interactions. The functional form of interaction energy for two molecules A and B is reported in the eq. 4 :

$$
E_{A B}=\sum_{i}^{A} \sum_{j}^{B}\left[\frac{q_{i} q_{j} e^{2}}{r_{i j}}+4 \epsilon_{i j}\left(\frac{\sigma_{i j}^{12}}{r_{i j}^{12}}-\frac{\sigma_{i j}^{6}}{r_{i j}^{6}}\right)\right] f_{i j}
$$

where $f_{i j}$ is equal to 0.5 (for $i, j=1,4$ ) and is equal to 1 for $i, j$ grater than 4 . All bonded and non-bonded parameters used in this work are listed in the Table S1 of Supporting Information. The parameters involving silicon atoms, such as bond and angle parameters between $\mathrm{Si}-\mathrm{O}, \mathrm{O}-\mathrm{Si}-\mathrm{O}, \mathrm{Si}-\mathrm{O}-\mathrm{H}$ groups, have been taken from the work of Barbier. ${ }^{27}$ The initial system has been simulated for $1 \mathrm{~ns}$ in the $N V T$ ensemble at $293 \mathrm{~K}$ and $1 \mathrm{~atm}$ by using GROMACS 4.5.4. ${ }^{38}$ A time step of $2 f s$ has been used for all simulations. The temperature and pressure have been controlled by using Berendsen thermostat ${ }^{39}$ with a $\tau_{p}$ of 10 $f s$. Periodic boundary conditions have been applied to all $x, y, z$ directions. After an initial energy minimization (500 steps) by using the steep-descent algorithm, all bonds have been constrained by using the LINCS algorithm. ${ }^{40}$ The non-bonded interactions were truncated at $1.0 \mathrm{~nm}$. After a short NVT simulation, a production run of $100 \mathrm{~ns}$ (NPT ensemble with $\tau_{p}=30 \mathrm{fs}$ ) has been performed starting from the last $N V T$ configuration. The composition of simulated systems is reported in Table 1.

Table 1: Composition of Systems.

\begin{tabular}{lrrrrccc}
\hline System & $\mathrm{CO}_{2}$ & $\mathrm{H}_{2} \mathrm{O}$ & BTHB & PMO & Tot. Nr. of Atoms & Temp. (K) & time (ns) \\
\hline 1 & 0 & 0 & 250 & 0 & 14400 & 293.15 & 100.0 \\
2 & 0 & 0 & 0 & 1 & 21600 & 293.15 & 100.0 \\
3 & 760 & 0 & 0 & 1 & 23880 & 195.15 & 100.0 \\
4 & 1168 & 0 & 0 & 1 & 25104 & 195.15 & 100.0 \\
5 & 3976 & 0 & 0 & 1 & 33528 & 195.15 & 100.0 \\
6 & 1000 & 1000 & 0 & 1 & 27600 & 195.15 & 100.0 \\
\hline
\end{tabular}




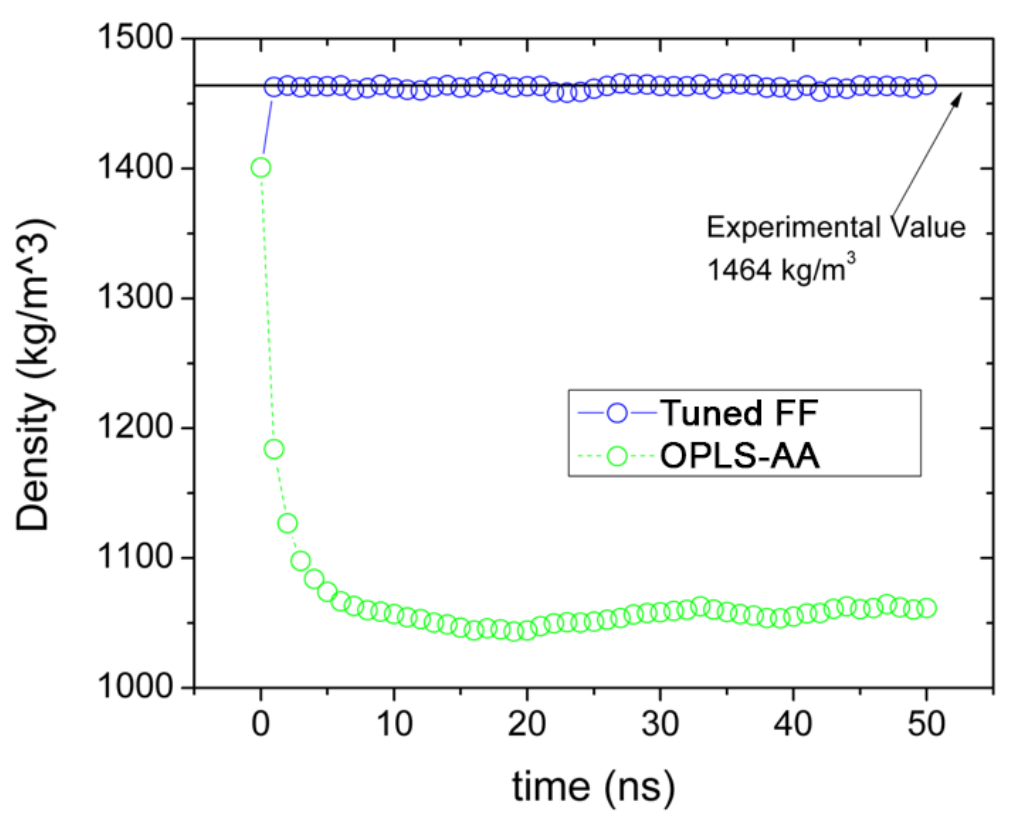

Figure 2: Comparison between mass density calculated by using OPLS-AA (green open circles) and the tuned force-field (blue open cirlce). The black line represents the experimental ${ }^{36}$ value of $1464 \mathrm{Kg} / \mathrm{m}^{3}$.

\section{Results and discussion}

By using the proposed model, we observed a high underestimation of the mass density, about $+28 \%$, together with a large deformation of the crystalline BTHB structure (Figure 2). Considering that the OPLS-AA force-field ${ }^{35}$ is able to reproduce the bulk mass density of organic liquid molecules within an error of about 2-4\%, and, considering that Barbier ${ }^{27}$ reported a correct reproduction of the mass density and crystalline structure of silica $\alpha$ quartz, the main problem arises from the treatment of interactions between silicon atoms with phenyl carbon atoms. Due to the lack in literature, to the best of our knowledge, of parameters describing interactions between silicon and carbon atoms in a chemical equivalent BTHB structure, we decided to perform ab initio calculations to get suitable parameters of such interactions. In particular, on a single molecule of BTHB, DFT calculations have been 
performed to get bond lengths, bending and torsion angles. We found that the description of torsional energy profile between $\mathrm{O}-\mathrm{Si}-\mathrm{C}-\mathrm{C}$ was critical in the correct reproduction of mass density and stability of structure of the BHTB crystal. From the energy profile of such torsional angle we obtained parameters, by mathematical fitting, to correctly describe both: energy barrier and shape of the torsional angle. As can be seen from Figure 3, the torsional barrier calculated from ab initio results to be very low, less than $1.0 \mathrm{Kcal} / \mathrm{mol}$. The resulting energy profile has been fitted to fine tune original OPLS-AA parameters. We used the same functional of torsional energy (3) as fitting function.
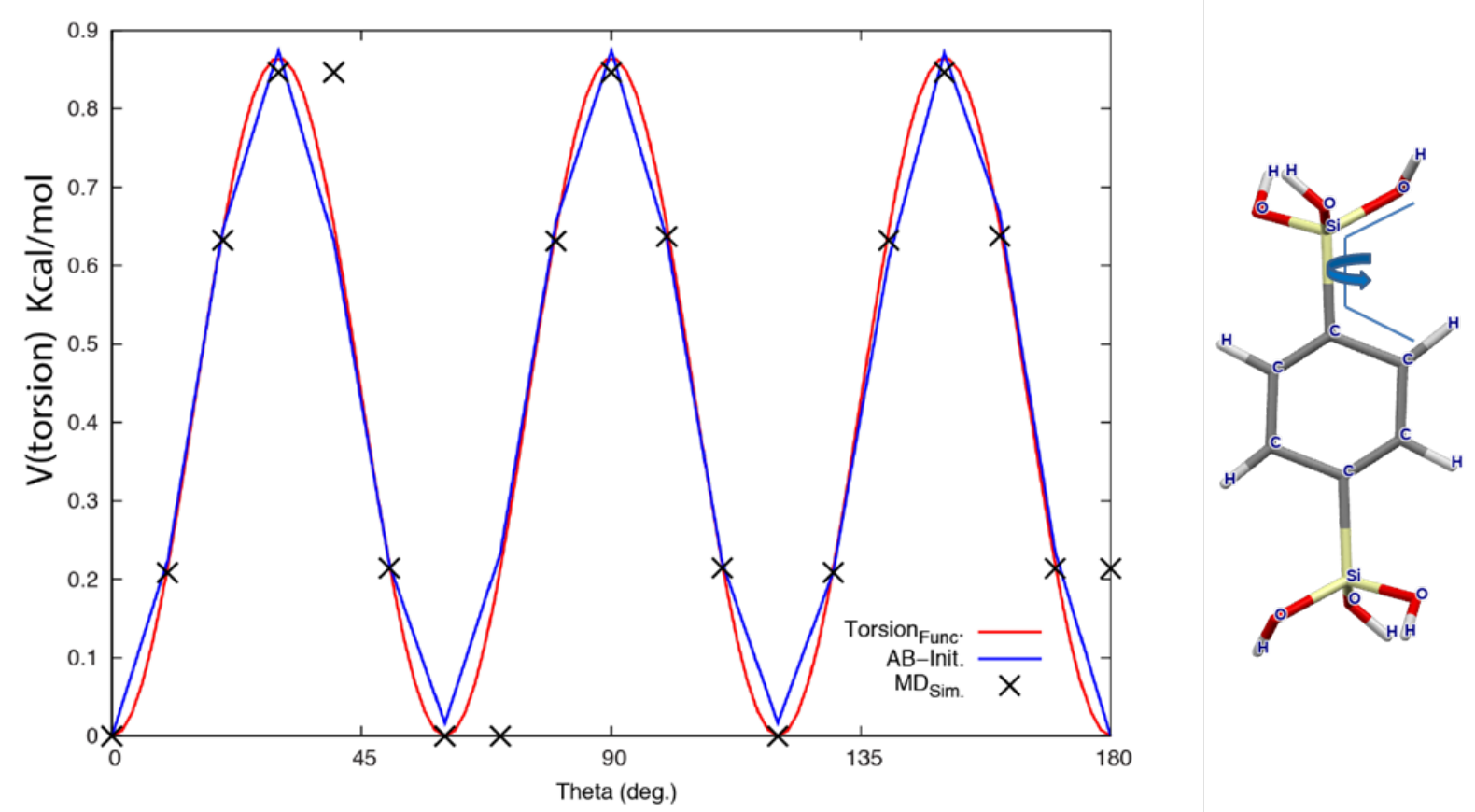

Figure 3: Comparison between the potential profile for $\mathrm{O}-\mathrm{Si}-\mathrm{C}-\mathrm{C}$ torsional angle (right side) obtained by: DFT calculations (blue line), fitted function (red line), and, from MD simulation (black cross). DFT calculations have been performed using Gaussian09 package ${ }^{41}$ at PBEH1PBE ${ }^{42}$ level of theory; the electronic configuration of all atoms has been described by the $6-13 \mathrm{G}(\mathrm{d}, \mathrm{p})$ basis set. ${ }^{43-45}$

By using tuned parameters for $\mathrm{O}-\mathrm{Si}-\mathrm{C}-\mathrm{C}$ torsional angle, a production run of 100 ns have been performed in the NPT ensemble, preceded by energy minimization and short $N V T$ simulation, as described in the previous section. A comparison of mass density calculated from the tuned force-field with those ones obtained from non optimized OPLS-AA ${ }^{35}$ and 
experimental data ${ }^{27}$ is reported in Figure 2. We found that the tuned force-field reproduces the mass density within an error of $1.6 \%$ with respect to experimental one. ${ }^{27}$ Even if the tuned force-field well reproduces the mass density, the stability of the crystal structure is not still retained. In particular, distortions of both: cell length axes $(a, b, c)$ and axes angles were observed. We have found that the treatment of the electrostatic interactions influences the stability of the crystalline cell parameters $(a, b, c, \alpha, \beta, \gamma)$.

The stability of crystal structure has been tested over the long range electrostatic treatment. In particular, we tested the tuned force-field with a cut-off at $0.9 \mathrm{~nm}$ with charge groups, and the non optimized OPLS-AA with a default cut-off of $1.0 \mathrm{~nm}$. As known from literature, ${ }^{46,47}$ charge groups were introduced to reduce the artifact due to the cut-off truncation of electrostatic interactions. In particular, by using plain cut-off scheme for Coulomb interactions, relevant jumps in the forces and electrostatic potential arise when partially charged atoms move out and in the cut-off. To overcome this artifact and reduce jumps in Coulombic potential, chemical moieties having total zero charge (charge group) are considered to be in or out the neighbor list. The charge group scheme adopted for the proposed model is reported in the Supporting Information. Time behavior of cell parameters $(a, b, c)$ obtained for different electrostatic treatment, together with snapshots of final configurations for OPLS-AA and tuned force-field, are reported in Figure 4.

As can be seen from the figure, optimized force field and plain cut-off (0.9 nm with charge groups) for the electrostatic interactions, guarantees a satisfactory reproduction of cell parameters. In particular, the cell parameters are reproduced within an error of about 1.8-2.2\% with respect to experimental ones. In addition, considering that we obtained similar results by using the Particle Mesh Ewald ${ }^{46}$, electrostatic treatment with plain cut-off is less expensive from the computational point of view with respect to PME $(N \log (N))$. This aspect become relevant for applications, such as studies involving the dynamic of molecular rotors (on $\mu s$ time scale), that are a peculiar future of PMO materials. it is worth noting that non optimized OPLS-AA overestimate the cell lengths of about 14-15\%, and differently 
(A)
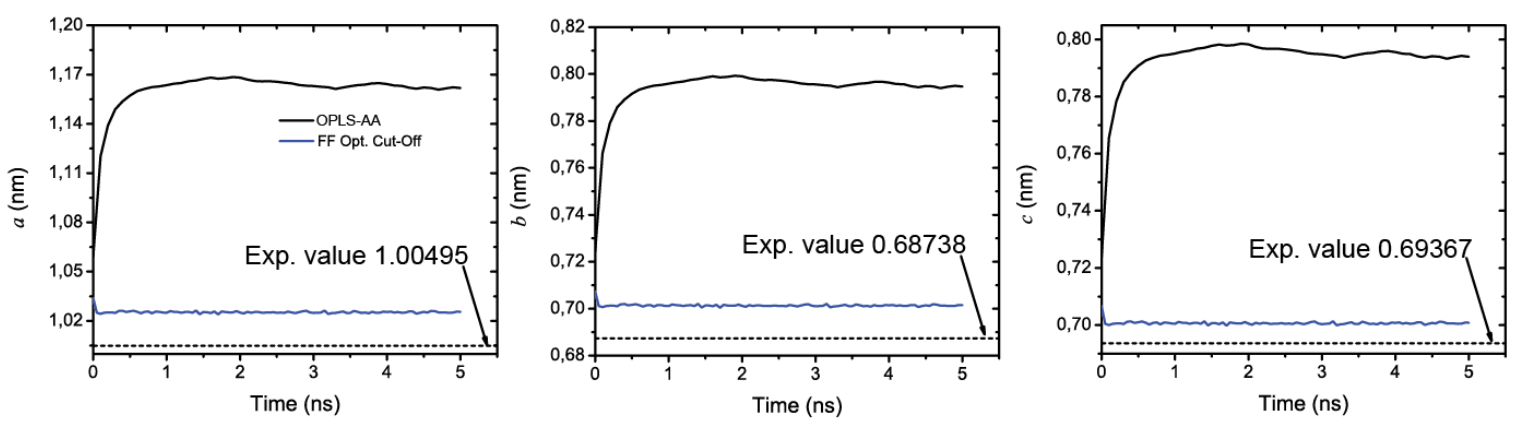

(B)

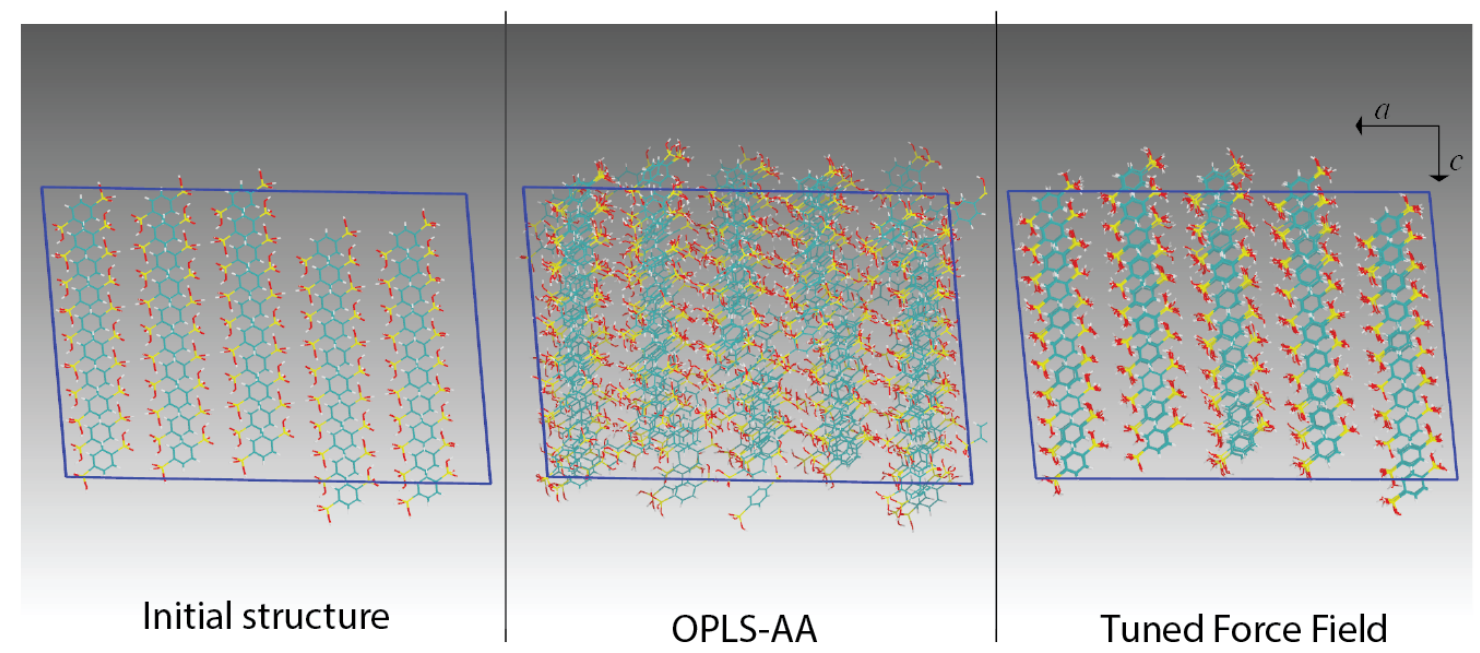

Figure 4: (A) Time behavior of cell parameters $a, b, c$ calculated for non optimized OPLS-AA and tuned force-field in which electrostatic potential are treated with different settings. The segmented black lines represent experimental values. ${ }^{27}$ All simulations have been performed in NPT ensemble in which the Berendsen barostat ${ }^{39}$ have been used. Anisotropic pressure coupling have been applied for all simulations. (B) Snapshots for the ac plane of BTHB crystal for: initial crystal structure, non optimized OPLS-AA and tuned force-field. 
from the case of optimized force field, the crystalline order is lost, as can be seen from the snapshots of Figure 4B. In order to quantify how much the order is retained in the structure obtained from the tuned force-field, X-Ray pattern has been calculated and compared with the experimental one. ${ }^{27}$ In Figure 5 the comparison between calculated and experimental $\mathrm{X}$-Ray pattern is reported.

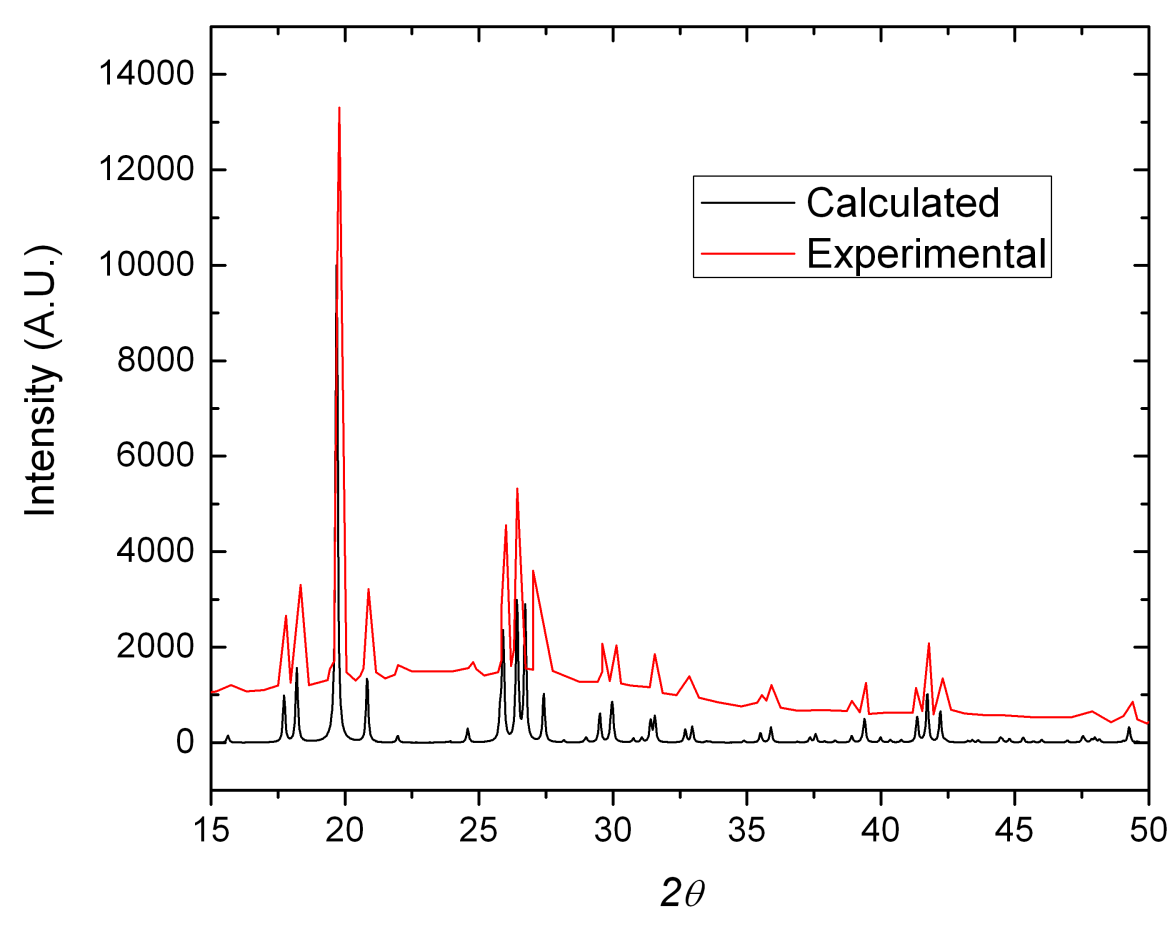

Figure 5: Comparison of X-Ray pattern between calculated (from NPT simulation with tuned force-filed) and experimental one ${ }^{27}$ (red line). Numerical Hartree-Fock wave functions $^{48}$ have been used for the X-Ray pattern calculation. X-Ray calculation has been performed by averaging 20 configurations over the last 5 nanoseconds of NPT simulation.

The calculated X-Ray pattern clearly shows that the structure obtained from MD simulations has a comparable periodicity as the experimental one. ${ }^{27}$ Moreover, the cell parameters have been reproduced within an error of about 1.8-2\% and the monoclinic space group $P 2_{1} / c$ is correctly retained belong NPT MD simulations. In addition, the tuned force-field correctly reproduce the mass density within an error of about $1.6 \%$ with respect to experimental value. ${ }^{27}$ The list of optimized parameters is reported in the Supporting Information. 


\section{Model of Mesoporous Organosilica}

The first example of complete crystal mesoporous organosilica has been reported by Inagaki et al., 1,13,18,19,24 which described the synthesis procedure to obtain the mesoporous $p$-phenylenesilica structure having a hexagonal array with a lattice constant of $5.25 \mathrm{~nm}$ and periodic channels of diameter of about $3.8 \mathrm{~nm}$. In particular, the pore walls have been found to have a periodicity with a spacing of $0.76 \mathrm{~nm}$ along channel direction in which alternate organic/inorganic layers are connected by $\mathrm{Si}-\mathrm{C}$ bonds. ${ }^{24} \mathrm{~A}$ schematic model of the mesoporous p-phenylenesilica is reported in Figure 6.

(A)

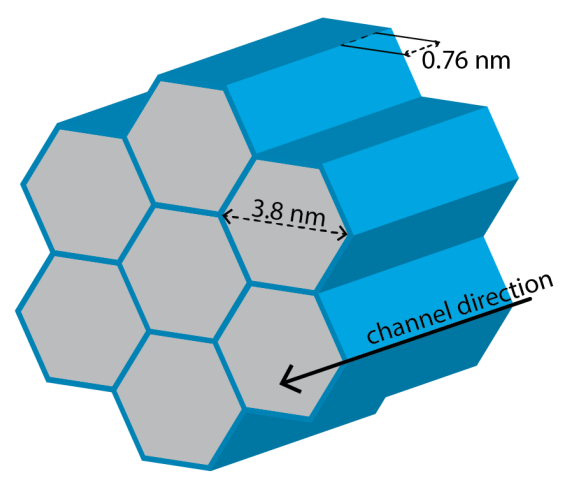

(B) Top view of BTHB crystal

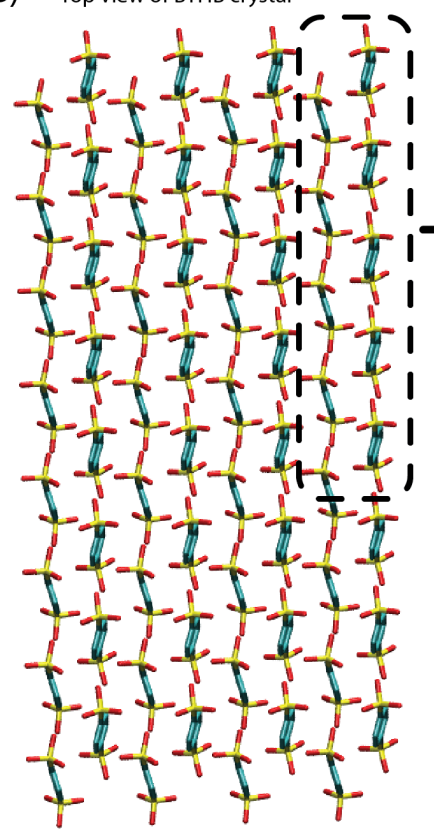

Top view p-phenylenesilica lattice

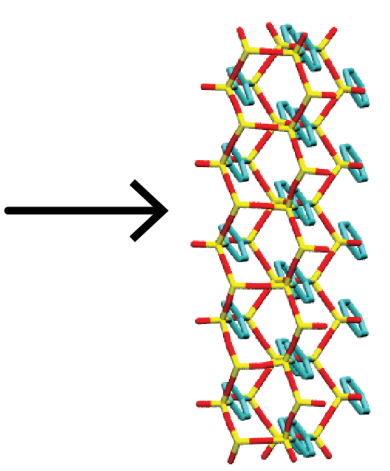

Lateral view p-phenylenesilica lattice

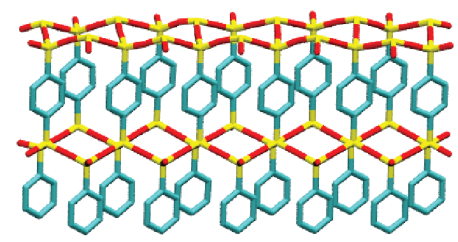

Figure 6: (A) Schematic model of Comparison of $p$-phenylenesilica. The wall periodicity of $0.76 \mathrm{~nm}$ and the channel diameter of $3.8 \mathrm{~nm}$ are indicated on the sketch. (B) Representation of of lattice model building process from the BTHB crystal structure. A slab of precursor PMOs crystal containing 22 phenyl rings, grouped in the black box, have been selected to be connected (by $\mathrm{OH}^{-}$removing) to form $p$-phenylenesilica lattice. Top and lateral views of the lattice are reported on the right of B panel. In yellow are represented silicon atoms, while, in red and green are reported oxygen and carbon atoms. Hydrogen atoms have been omitted for clarity.

In the following is described the procedure to build the periodic mesoporous crystalline structure with hexagonal framework including explicitly nanochannels. In particular, we 
used as minimal brick element to build the whole structure, a single interconnected wall, as reported in Figure 7A. 12 replicas of the single wall (minimal brick element) have been oriented in a way to obtain a mesoporous repeating unit. Then, each wall has been properly connected, with others, by replacing pendant hydroxyl groups $\mathrm{OH}$ - with $\mathrm{Si}-\mathrm{O}-\mathrm{Si}$ covalent bonds. The final repeating unit, containing a whole nanochannel, has reported in the Figure 7B (continuous black line). Connecting 4 repeating units, as depicted in the scheme of Figure 7B, the fully connected periodic crystalline structure is obtained. A snapshot of the structure is reported in the panel $\mathrm{C}$ of Figure 7.

(A)

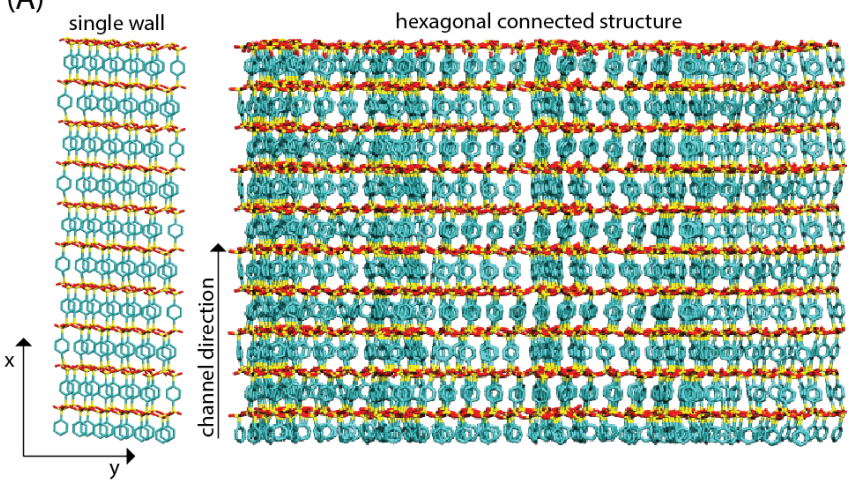

(B)

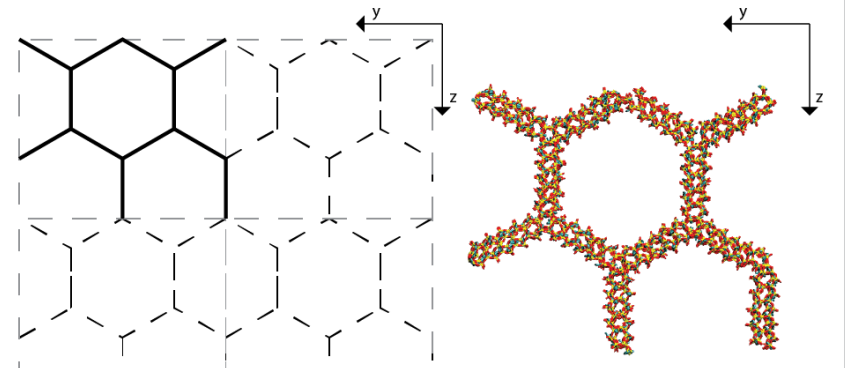

(C)

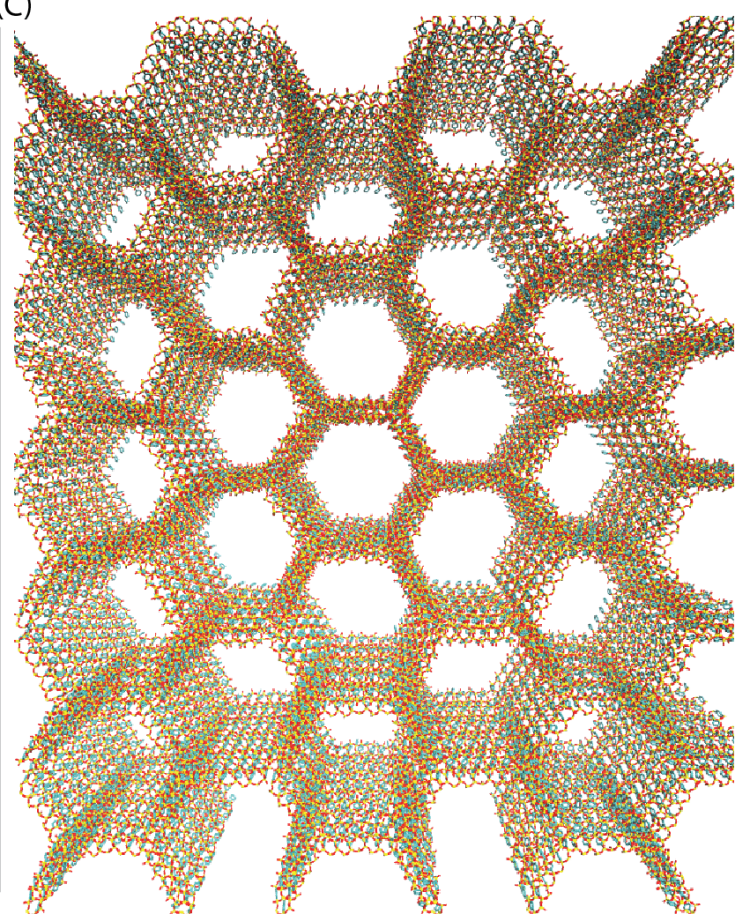

Figure 7: (A) View along channel direction of both: single wall and assembled hexagonal crystalline unit. (B) Scheme illustrating the repeating unit (black continuous line) and periodic images along $y, z$ plane (segmented black line). The top view of the repeating unit structure is also reported. (C) Top view of periodic mesoporous structure in which nanochannels are reported. In all reported structures the hydrogen atoms have been omitted for clarity.

The final mesoporouse structure, obtained by following the described procedure, has been used as starting point for MD simulations. In particular, a minimization of structure (250 steps), using steep-descent algorithm, have been performed. On the minimized structure a 


\section{Gas Inclusion}

Due to the mesoporosity and high surface area ${ }^{2,3,7}$ (up to $2730 \mathrm{~m}^{2} / \mathrm{g}$ ), gas adsorption capability (such as $\mathrm{CO}_{2}, \mathrm{CH}_{4}$, benzene, $\mathrm{N}_{2}$ and $\mathrm{NH}_{3}$ ) of PMOs has been recently measured. ${ }^{3,7}$ In particular, $\mathrm{IR}^{49-51}$ and solid-state NMR experiments ${ }^{3}$ proved that $p$-phenylenesilica has high capability to adsorb $\mathrm{CO}_{2}$ molecules (up to $88 \%$ by weight at $195 \mathrm{~K}$ ). In addition, DFT calculations have been performed to study interactions of $\mathrm{CO}, \mathrm{CH}_{4}$ and $\mathrm{CO}_{2}$ molecules in a periodic wall of $p$-phenylenesilica. ${ }^{25}$ In the following we report the simulation results of gas included in the pores, interacting with organic/inorganic layers, for four different systems. In particular, we simulated three systems in which $\mathrm{CO}_{2}$ ranges from 4.0 to $22.5 \%$ by weight, and, an additional system containing $5.6 \%$ of $\mathrm{CO}_{2}$ and $2.4 \%$ of $\mathrm{H}_{2} \mathrm{O}$, respectively (systems 3-6 of Table 1). Gas molecules have been randomly inserted in the PMO nanochannel free 
(A)
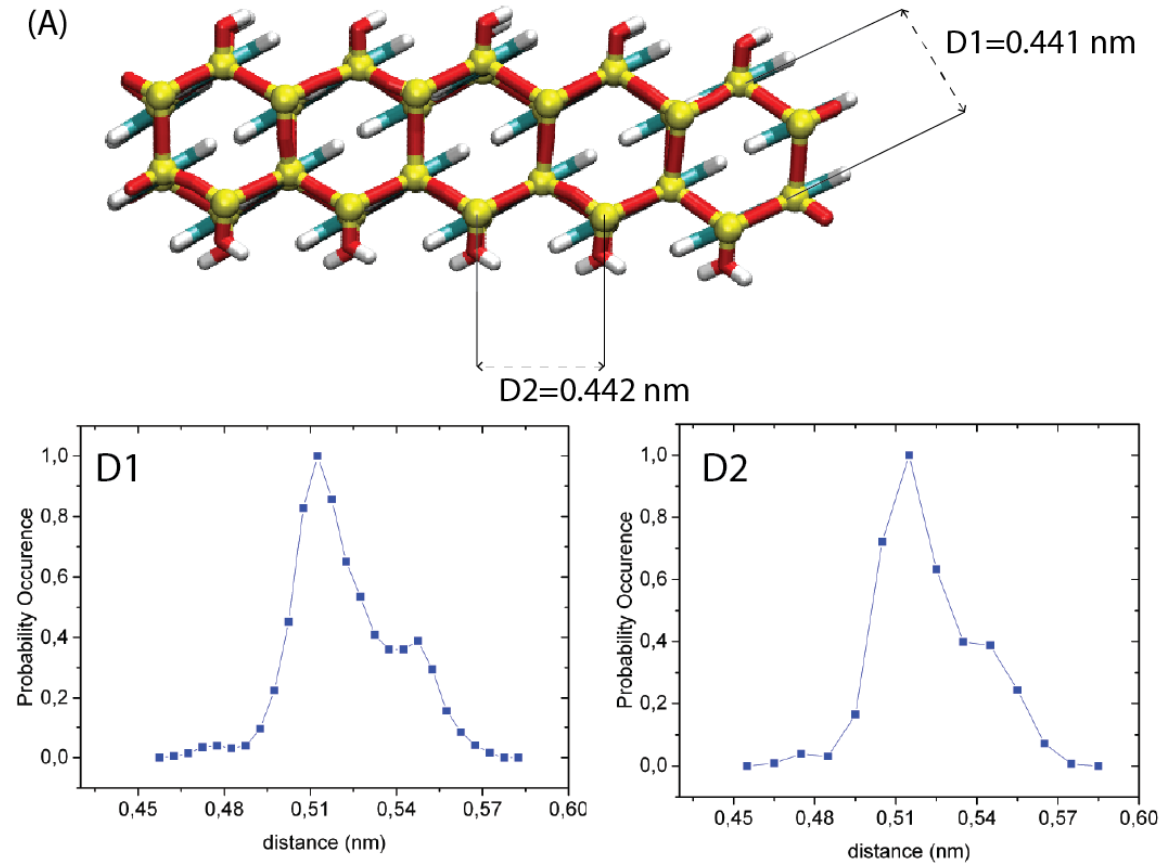

(B)
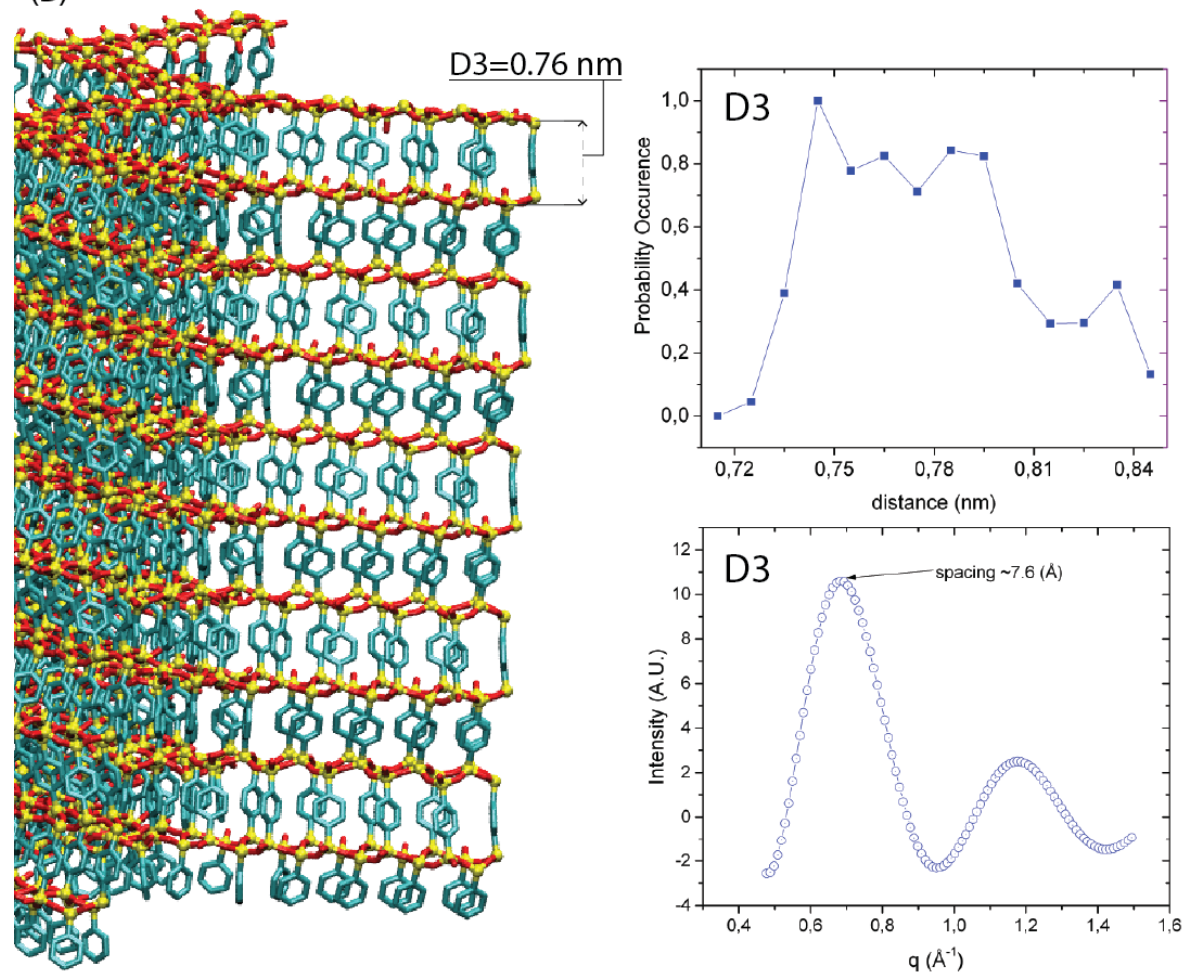

Figure 8: (A) Snapshots illustrating experimental distances ${ }^{24}$ D1 and D2 between silicon atoms belonging the same layer of mesoporous structure. The distance distributions calculated from the NPT simulation are reported in the same panel. (B) View of mesoporous pore along channel parallel direction. The experimental distance ${ }^{24} \mathrm{D} 3$ between silicon atoms belonging two consecutive layers is reported. On the right side panel, calculated distance distribution D3 and the X-Ray pattern relative to the specific periodicity are reported. 
volume by using packmol code. ${ }^{52}$ Similar simulation protocol described in the previous section has been applied to all systems containing gases molecules. For $\mathrm{CO}_{2}$ molecule type OPLS-AA ${ }^{35}$ parameters have been used, while, SPCE model ${ }^{53}$ has been considered for $\mathrm{H}_{2} \mathrm{O}$ molecule type. In order to understand the effect of the $\mathrm{CO}_{2}$ concentration on the interaction with PMO walls, radial distribution functions (RDF) for different atom pairs have been calculated. A comparison of RDF is reported in Figure 9.
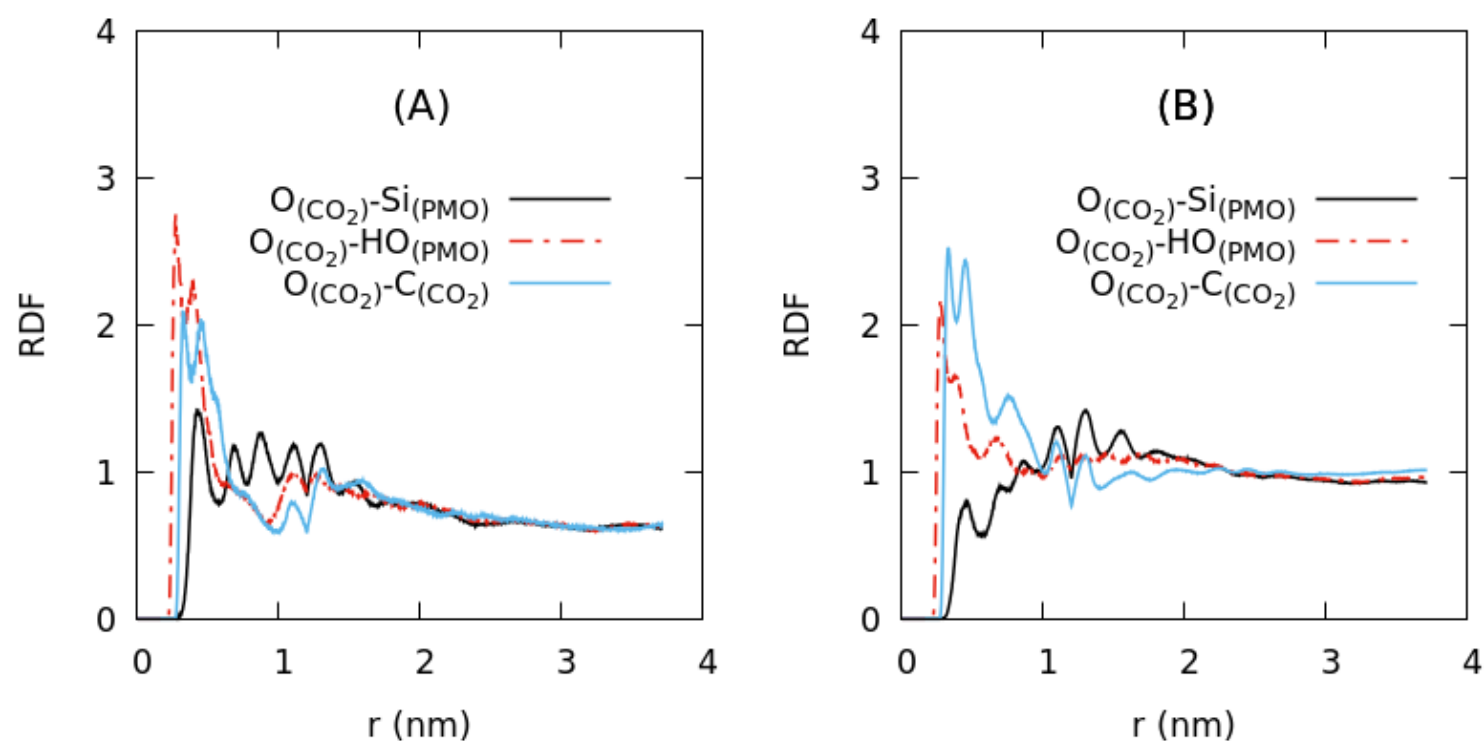

Figure 9: RDF calculated for the pairs: $\mathrm{O}_{(\mathrm{CO} 2)}-\mathrm{Si}_{(\mathrm{PMO})}$ (black line), $\mathrm{O}_{(\mathrm{CO} 2)}-\mathrm{OH}_{(\mathrm{PMO})}$ (red segmented line) and $\mathrm{O}_{(\mathrm{CO} 2)}-\mathrm{C}_{(\mathrm{CO} 2)}$ (blue line). (A) System 3, (B) System 5 in Table 1. The RDF analysis has been performed by averaging configurations belonging the last $5 \mathrm{~ns}$ of each simulation.

In particular, we compared RDFs for systems at 4.0 and $22.5 \% \mathrm{w} / \mathrm{w}$ of content of $\mathrm{CO}_{2}$. In the first case (Figure 9A) it is clear as $\mathrm{CO}_{2}$ molecules interact more favorable with the pendant hydroxyl groups $\mathrm{OH}_{(\mathrm{PMO})}$ exposed inside nanochannels of PMO compared to same $\mathrm{CO}_{2}$ molecules (blue line), in agreement with the result of Pacchioni ${ }^{25}$ obtained from DFT calculations. In the second case, when the $\mathrm{CO}_{2}$ amount increases $(22.5 \%$ (w/w) $)$, the self interactions between $\mathrm{CO}_{2}-\mathrm{CO}_{2}$ molecules became more probable with the respect to those ones $\mathrm{CO}_{2}-\mathrm{OH}_{(\mathrm{PMO})}$, as reported in Figure $9 \mathrm{~B}$. Moreover, the peak at $\approx 0.6 \mathrm{~nm}$ of $\mathrm{CO}_{2}-\mathrm{CO}_{2}$ (blue curve) confirms the presence of $\mathrm{CO}_{2}$ second shell molecules only at high carbon dioxide 
content. Using geometrical criteria, based on position and width of peaks in RDF calculated for $\mathrm{CO}_{2}-\mathrm{CO}_{2}$ pair, molecules belonging first and second shell have been grouped. A representation of the two shell molecule types is sketched in Figure 10.

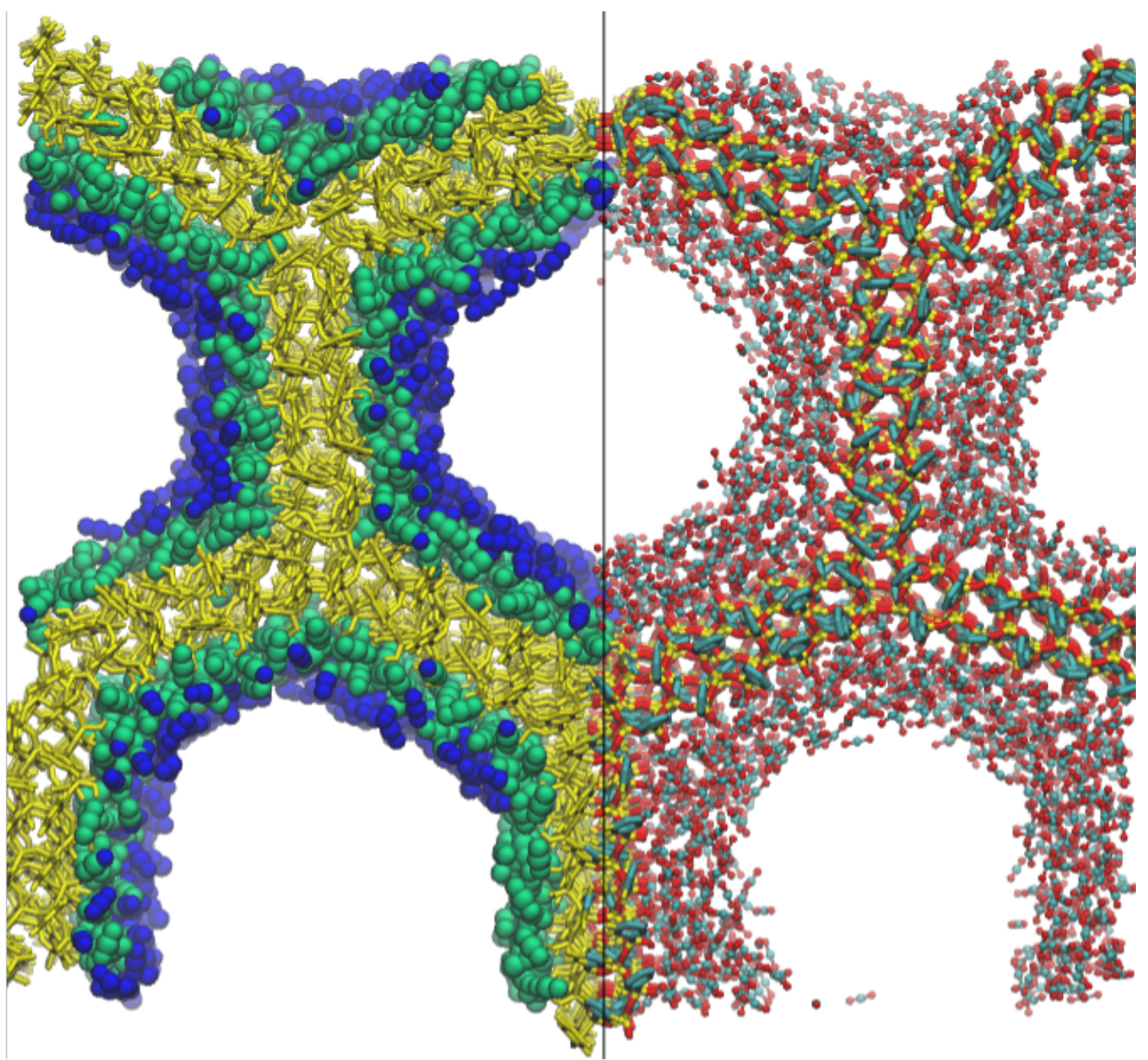

Figure 10: Snapshot of PMO configuration at $22.5 \% \mathrm{w} / \mathrm{w}$ of $\mathrm{CO}_{2}$. The left side of the snapshot shows PMO structure in yellow and two different $\mathrm{CO}_{2}$ molecule types, in green belonging the first shell and in blue belonging to second shell type. On the right side of the figure a standard visualization based on different atom types is reported. Hydrogen atoms have been not included for clarity.

The presence of a $\mathrm{CO}_{2}$ second shell molecule has effect also on the self diffusion coefficient $D$ of carbon dioxide. $D$ were calculated from the linear fitting of the mean square displacement of the Einstein relation ${ }^{46}$ : 


$$
D=\lim _{t \rightarrow \infty} \frac{1}{6 t}\left\langle\left|\mathbf{r}_{i}(t)-\mathbf{r}_{i}(0)\right|^{2}\right\rangle
$$

The results including global and components along $x, y, z$ directions of the diffusion coefficients are reported in Table 2. As general result, as expected, the diffusion is significantly reduced in confined $y, z$ directions (see panel B of Figure 7). Instead, along non confined direction parallel to the nanochannel axis, $D x$ result to be $\approx 2$ times larger. Moreover, the formation of a stable second shell (at high $\mathrm{CO}_{2}$ content, system 5 Table 2), reduces the mobility of carbon dioxide molecules, of a factor about 2, along confined and non confined directions. Time behavior of MSD are reported in the Supporting Information.

Table 2: Global and $x, y, z$ components of $D\left(10^{-5} \mathrm{~cm}^{2} \mathrm{~s}^{-1}\right)$ calculated for $\mathrm{CO}_{2}$ molecules.

\begin{tabular}{cccccc}
\hline System & $\mathrm{CO}_{2} \%_{(\mathrm{w} / \mathrm{w})}$ & $D$ & $D x$ & $D y$ & $D z$ \\
\hline 3 & 4.0 & $0.076(0.008)$ & $0.12(0.01)$ & $0.046(0.007)$ & $0.060(0.001)$ \\
4 & 6.6 & $0.076(0.004)$ & $0.128(0.001)$ & $0.051(0.001)$ & $0.049(0.006)$ \\
5 & 22.5 & $0.035(0.001)$ & $0.056(0.005)$ & $0.026(0.001)$ & $0.025(0.001)$ \\
\hline
\end{tabular}

We also investigated difference in the gas/PMO wall interaction for $\mathrm{CO}_{2}$ and $\mathrm{H}_{2} \mathrm{O}$ molecules. To this aim an additional system at $1: 1 \mathrm{CO}_{2}: \mathrm{H}_{2} \mathrm{O}$ (system 6 in Table 1) were simulated. The RDF comparison in Figure 11A shows a slightly stronger interaction of $\mathrm{CO}_{2}$ in favor of PMO compared to $\mathrm{H}_{2} \mathrm{O}$. Moreover, a stronger interaction between $\mathrm{H}_{2} \mathrm{O}-\mathrm{CO}_{2}$, with the respect to the $\mathrm{H}_{2} \mathrm{O}$-hydroxyl groups belonging PMO walls is found (Figure 11B).

This behavior were confirmed, also, comparing the hydrogen bond (H-Bond) fraction between $\mathrm{H}_{2} \mathrm{O}$ and both: PMO hydroxyl groups and $\mathrm{CO}_{2}$ molecules, as reported in Figure $12 \mathrm{~A}$. In particular, we have found water molecules to form H-bonds more probable with $\mathrm{CO}_{2}$ molecules instead of pendant hydroxyl groups of PMO. Moreover, no relevant differences between donor-acceptor distance distributions and hydrogen bond lifetimes for the two different H-bonds (with $\mathrm{CO}_{2}$ and $\mathrm{HO}-\mathrm{PMO}$ ) have been found (Figure 12B, C).

The presence of high number of $\mathrm{H}$-bonds between $\mathrm{CO}_{2}$ and $\mathrm{H}_{20}$ influences also dynamic 

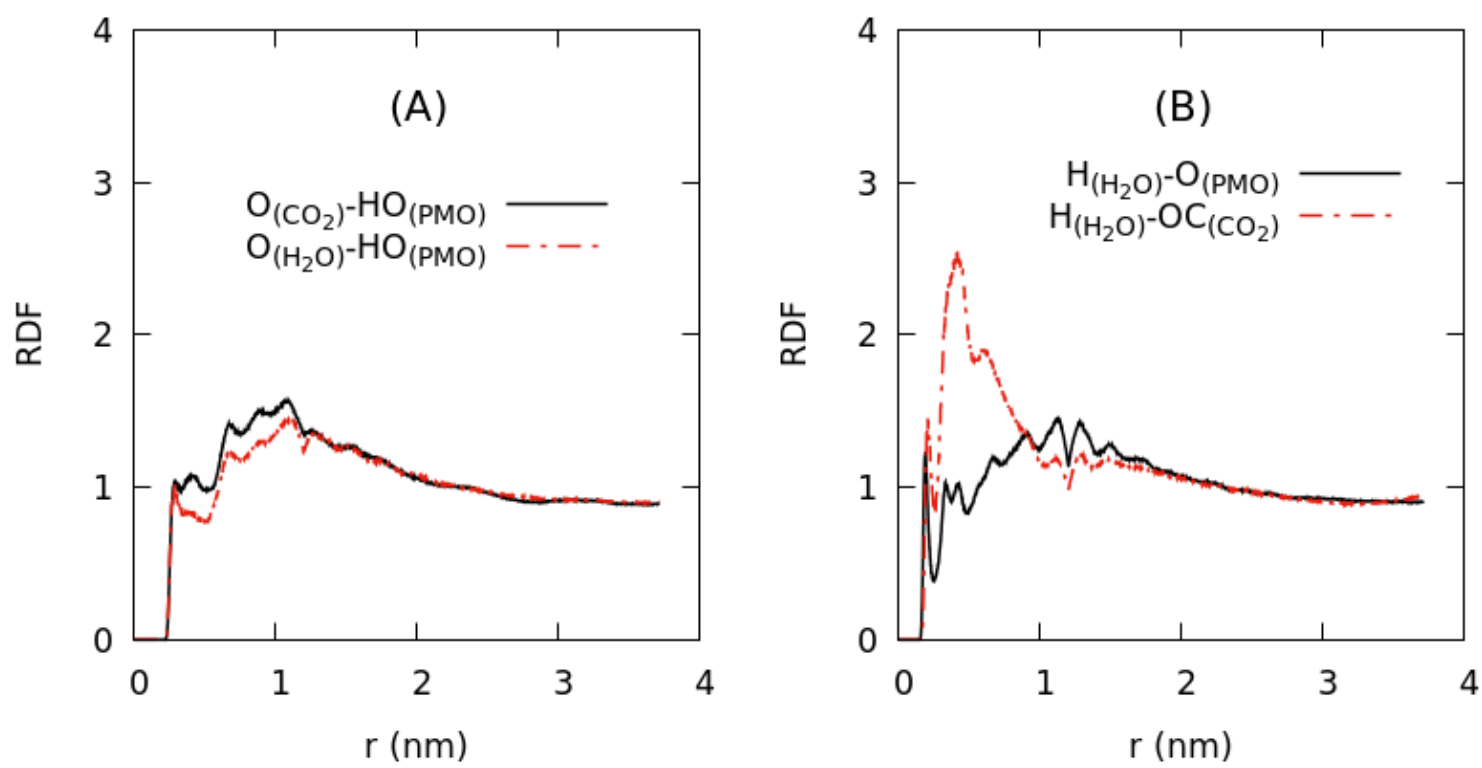

Figure 11: RDF calculated for the pairs: (A) $\mathrm{O}_{\left(\mathrm{CO}_{2}\right)}-\mathrm{OH}_{(\mathrm{PMO})}$ (black line), $\mathrm{O}_{\left(\mathrm{H}_{2} \mathrm{O}\right)}-\mathrm{OH}_{(\mathrm{PMO})}$ (red segmented line), and (B) $\mathrm{H}_{\left(\mathrm{H}_{2} \mathrm{O}\right)}-\mathrm{O}_{(\mathrm{PMO})}$ (black line), $\mathrm{H}_{\left(\mathrm{H}_{2} \mathrm{O}\right)}-\mathrm{O}_{\left(\mathrm{CO}_{2}\right)}$ (red segmented line). The RDF analysis has been performed by averaging configurations belonging the last $5 n s$ of the simulation.
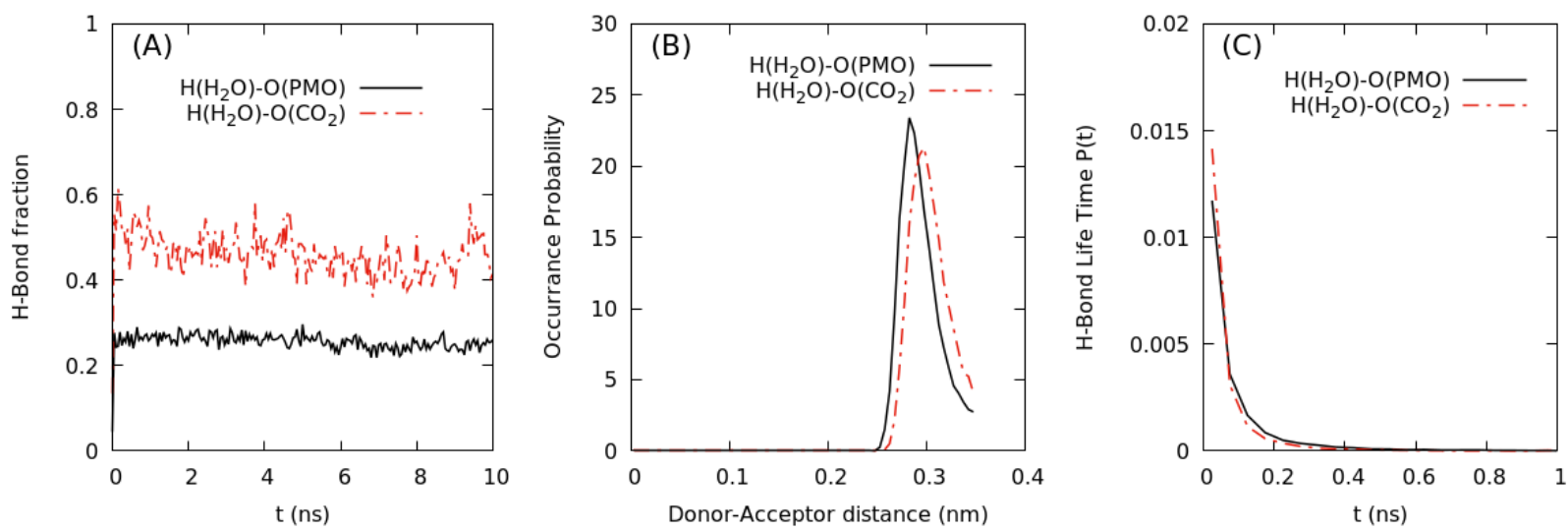

Figure 12: (A) Time behavior of H-Bond fraction. (B) Distribution of Donor-Acceptor distance, defined as the distance between $\mathrm{AO}(\mathrm{A}-\mathrm{H}-\mathrm{O})$. (C) Hydrogen bond lifetime. The $\mathrm{H}$-Bonds have been calculated considering as geometrical criteria ${ }^{54}$ a cut-off distance of $0.3 \mathrm{~nm}$ and angle between acceptor-donor groups A-H-O $\theta=120^{\circ}$. Oxygen atoms of both: carbon dioxide and hydroxyl group of PMO are considered hydrogen bond acceptor A, while, $\mathrm{H}-\mathrm{O}$ groups of water molecules are considered as donors. 
properties. In fact, do to formation of a $\mathrm{H}$-bond network, the diffusion of $\mathrm{CO}_{2}$ molecules is found to be reduced of a factor $\approx 1.7$ even the $\%(\mathrm{w} / \mathrm{w})$ is low $(5.6)$, as reported in Table 3.

Table 3: Global and $x, y, z$ components of $D\left(10^{-5} \mathrm{~cm}^{2} s^{-1}\right)$ calculated for $\mathrm{CO}_{2}$ and $\mathrm{H}_{2} \mathrm{O}$ molecules (system 6 of Table 1 ).

\begin{tabular}{ccccc}
\hline Molecule & $D$ & $D x$ & $D y$ & $D z$ \\
\hline $\mathrm{CO}_{2}$ & $0.043(0.001)$ & $0.642(0.003)$ & $0.027(0.005)$ & $0.03(0.01)$ \\
$\mathrm{H}_{2} \mathrm{O}$ & $0.003(0.001)$ & $0.004(0.001)$ & $0.002(0.001)$ & $0.002(0.001)$ \\
\hline
\end{tabular}

\section{Conclusions}

We provided a validation and optimization of OPLS-AA force field to model at all atom level periodic crystalline mesoporous $p$-phenylenesilica. In particular, the mesoporous hexagonal framework structure, including explicitly nanochannels, have been validated on the reproduction of experimental periodic distance distributions. ${ }^{24}$ DFT calculations have been used to correctly parametrize torsional potential of phenyl rings belonging organic layers connected with inorganic silicon atoms. Furthermore, gas inclusion and gas/PMO wall interactions have been investigated for $\mathrm{CO}_{2}$ and $\mathrm{H}_{2} \mathrm{O}$ molecules. No significant differences have been found for these two gases with only a slightly stronger interactions of $\mathrm{CO}_{2} / \mathrm{PMOs}$ nanochannel with respect to water molecules. Instead, dynamic properties, such as diffusion coefficient $D$, has been found to be dependent from gas amount and composition. In the first case, at high $\mathrm{CO}_{2}$ content, a mobility reduction of carbon dioxide molecules is observed due to the formation of a second shell of $\mathrm{CO}_{2}$ molecules. Also in the second case the diffusion of carbon dioxide molecules is reduced thanks to the formation of a strong hydrogen bond network between $\mathrm{CO}_{2}$ and $\mathrm{H}_{2} \mathrm{O}$ molecules. 


\section{Acknowledgement}

G.M and A.D.N. wish to thank the HPC team of Enea (http://www.enea.it) for using the ENEA-GRID and the HPC facilities CRESCO (http://www.cresco.enea.it) in Portici. A.C. would like to thank Cariplo Foundation (Balance project), PRIN 2016 and INSTM Consortium/Lombardy Region for financial support.

\section{Supporting Information Available}

Supporting Information includes: optimized parameters for PMO structure, adopted charge and group charge scheme, additional plot of MSD for all simulated systems including gases in the nanochannel.

This material is available free of charge via the Internet at http://pubs.acs.org/.

\section{References}

(1) Mizoshita, N.; Tani, T.; Inagaki, S. Chem. Soc. Rev. 2011, 40, 789-800.

(2) Xia, Y.; Mokaya, R. Microporous and Mesoporous Materials 2005, 86, 231 - 242.

(3) Comotti, A.; Bracco, S.; Valsesia, P.; Ferretti, L.; Sozzani, P. Journal of the American Chemical Society 2007, 129, 8566-8576, PMID: 17579407.

(4) Angiolina, C.; Silvia, B.; Mario, B.; Jacopo, P.; Mauro, G.; Piero, S. Chemistry - A European Journal 2015, 21, 18209-18217.

(5) Angiolina, C.; Silvia, B.; Patrizia, V.; Mario, B.; Piero, S. Angewandte Chemie International Edition 2010, 49, 1760-1764.

(6) Bracco, S.; Comotti, A.; Valsesia, P.; Chmelka, B. F.; Sozzani, P. Chemical Communications 2008, 4798-4800. 
(7) Wei, Y.; Li, X.; Zhang, R.; Liu, Y.; Wang, W.; Ling, Y.; El-Toni, A. M.; Zhao, D. Scientific Reports 2016, 6, 20769 EP -, Article.

(8) Frank, H.; Maximilian, C.; Jürgen, M.; Michael, F. Angewandte Chemie International Edition 2006, 45, 3216-3251.

(9) Bracco, S.; Beretta, M.; Cattaneo, A.; Comotti, A.; Falqui, A.; Zhao, K.; Rogers, C.; Sozzani, P. Angewandte Chemie International Edition 54, 4773-4777.

(10) Wendong, W.; E., L. J.; A., O. G. Small 2010, 6, 2634-2642.

(11) Chen, C.; Kim, J.; Ahn, W.-S. Korean Journal of Chemical Engineering 2014, 31, $1919-1934$.

(12) Chua, Y. T.; Lin, C. X. C.; Kleitz, F.; Zhao, X. S.; Smart, S. Chemical Communications 2013, 49, 4534-4536.

(13) Inagaki, S.; Guan, S.; Fukushima, Y.; Ohsuna, T.; Terasaki, O. Journal of the American Chemical Society 1999, 121, 9611-9614.

(14) Asefa, T.; MacLachlan, M. J.; Coombs, N.; Ozin, G. A. Nature 1999, 402, 867 EP -.

(15) Melde, B. J.; Holland, B. T.; Blanford, C. F.; Stein, A. Chemistry of Materials 1999, $11,3302-3308$.

(16) Hoffmann, F.; Cornelius, M.; Morell, J.; Fröba, M. Angewandte Chemie International Edition 2006, 45, 3216-3251.

(17) Loy, D. A.; Shea, K. J. Chemical Reviews 1995, 95, 1431-1442.

(18) Fujita, S.; Inagaki, S. Chemistry of Materials 2008, 20, 891-908.

(19) Kapoor, M. P.; Yang, Q.; Inagaki, S. Journal of the American Chemical Society 2002, $124,15176-15177$. 
(20) Hunks, W. J.; Ozin, G. A. Journal of Materials Chemistry 2005, 15, 3716-3724.

(21) Jonas, C.; Xavier, C.; Chi, M. M. W.; Audrey, G.; Laurence, R.; Philippe, T.; Marie, M.; Jean-Olivier, D. Advanced Materials 2014, 26, 6174-6180.

(22) Fangqiong, T.; Linlin, L.; Dong, C. Advanced Materials 2012, 24, 1504-1534.

(23) Park, S. S.; Santha Moorthy, M.; Ha, C.-S. Npg Asia Materials 2014, 6, e96 EP -, Review.

(24) Inagaki, S.; Guan, S.; Ohsuna, T.; Terasaki, O. Nature 2002, 416, 304.

(25) Martinez, U.; Pacchioni, G. Microporous and mesoporous materials 2010, 129, 62-67.

(26) Rimsza, J. M.; Yeon, J.; van Duin, A. C. T.; Du, J. The Journal of Physical Chemistry C 2016, 120, 24803-24816.

(27) Barbier, D.; Brown, D.; Grillet, A.-C.; Neyertz, S. Macromolecules 2004, 37, 46954710.

(28) Rimsza, J. M.; Jones, R. E.; Criscenti, L. J. Langmuir 2017, 33, 3882-3891.

(29) M., R. J.; E., J. R.; J., C. L. Journal of the American Ceramic Society 2017, 101, 1488-1499.

(30) Jincheng, D.; N., C. A. Journal of the American Ceramic Society 2005, 88, 2532-2539.

(31) Bandura, A. V.; Kubicki, J. D.; Sofo, J. O. The Journal of Physical Chemistry C 2011, $115,5756-5766$.

(32) Skelton, A. A.; Wesolowski, D. J.; Cummings, P. T. Langmuir 2011, 27, 8700-8709.

(33) Rimsza, J. M.; Deng, L.; Du, J. Journal of Non-Crystalline Solids 2016, 431, 103-111.

(34) Yeon, J.; van Duin, A. C. T. The Journal of Physical Chemistry C 2016, 120, 305-317. 
(35) Jorgensen, W. L.; Maxwell, D. S.; Tirado Rives, J. Journal Of The American Chemical Society 1996, 118, 11225-11236.

(36) Cerveau, G.; Corriu, R. J. P.; Dabiens, B.; Le Bideau, J. Angewandte Chemie International Edition 2000, 39, 4533-4537.

(37) Macrae, C. F.; Bruno, I. J.; Chisholm, J. A.; Edgington, P. R.; McCabe, P.; Pidcock, E.; Rodriguez-Monge, L.; Taylor, R.; van de Streek, J.; Wood, P. A. Journal of Applied Crystallography 2008, 41, 466-470.

(38) Van der Spoel, D.; Lindahl, E.; Hess, B.; Groenhof, G.; Mark, A. E.; Berendsen, H. J. C. Journal of Computational Chemistry 2005, 26, 1701-1718.

(39) Berendsen, H. J. C.; Postma, J. P. M.; Gunsteren, W. F. v.; DiNola, A.; Haak, J. R. Journal of Chemical Physics 1984, 81, 3684-3690.

(40) Hess, B.; Bekker, H.; Berendsen, H. J. C.; Fraaije, J. G. E. M. Journal of Computational Chemistry 1997, 18, 1463-1472.

(41) Frisch, M. J. et al. Gaussian 09 Revision C.01. Gaussian, Inc.: Wallingford, CT, 2009.

(42) Ernzerhof, M.; Perdew, J. P. The Journal of Chemical Physics 1998, 109, 3313-3320.

(43) Ditchfield, R.; Hehre, W. J.; Pople, J. A. The Journal of Chemical Physics 1971, 54, $724-728$.

(44) Petersson, G. A.; Bennett, A.; Tensfeldt, T. G.; AlLaham, M. A.; Shirley, W. A.; Mantzaris, J. The Journal of Chemical Physics 1988, 89, 2193-2218.

(45) Petersson, G. A.; AlLaham, M. A. The Journal of Chemical Physics 1991, 94, 60816090.

(46) Allen, M. P.; Tildesley, D. J. Computer simulation of liquids; Oxford university press, 2017. 
(47) Frenkel, D.; Smit, B. Understanding molecular simulation: from algorithms to applications; Elsevier, 2001; Vol. 1.

(48) Cromer, D. T.; Mann, J. B. Acta Crystallographica Section A 1968, 24, 321-324.

(49) Hoffmann, F.; Gngerich, M.; Klar, P. J.; Frba, M. The Journal of Physical Chemistry C 2007, 111, 5648-5660.

(50) Onida, B.; Borello, L.; Busco, C.; Ugliengo, P.; Goto, Y.; Inagaki, S.; Garrone, E. The Journal of Physical Chemistry B 2005, 109, 11961-11966, PMID: 16852474.

(51) Camarota, B.; Ugliengo, P.; Garrone, E.; Arean, C. O.; Delgado, M. R.; Inagaki, S.; Onida, B. The Journal of Physical Chemistry C 2008, 112, 19560-19567.

(52) Martnez, L.; Andrade, R.; Birgin, E. G.; Martnez, J. M. Journal of Computational Chemistry 30, 2157-2164.

(53) Berendsen, H. J. C.; Grigera, J. R.; Straatsma, T. P. The Journal of Physical Chemistry 1987, 91, 6269-6271.

(54) van der Spoel, D.; van Maaren, P. J.; Larsson, P.; Tîmneanu, N. The Journal of Physical Chemistry B 2006, 110, 4393-4398. 


\section{Graphical TOC Entry}

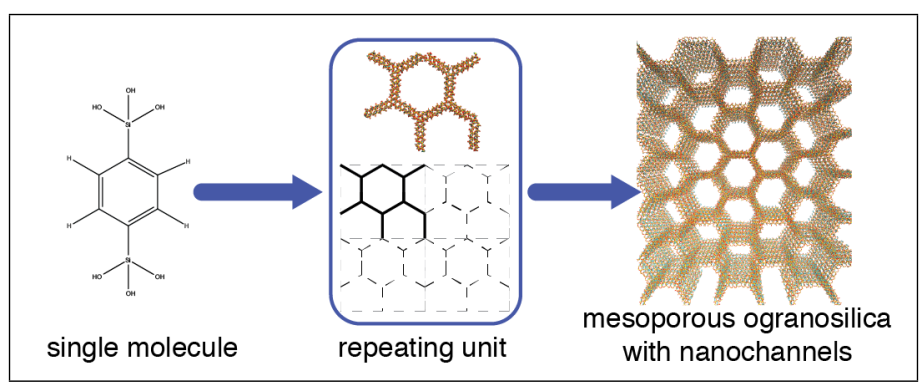

15

16

17

18

19

20

21

22

23

24

25

26

27

28

29

30

31

32

33

34

35

36

37

38

39

40

41

42

43

44

45

46

47

48

49

50

51

52

53

54

55

56

57

58

59

60 